\title{
Anaplastic thyroid cancer: outcomes of trimodal therapy
}

\author{
Orla A. Houlihan ${ }^{1}$, Richard Moore ${ }^{1}$, Muhammad F. Jamaluddin ${ }^{1}$, Adrinda Sharifah ${ }^{2}$, Henry Paul Redmond ${ }^{3}$, \\ Seamus O'Reilly ${ }^{4}$, Linda Feeley ${ }^{5,6}$, Patrick Sheahan ${ }^{2,6}$, Kathy Rock ${ }^{1,6}$ \\ ${ }^{1}$ Department of Radiation Oncology, Cork University Hospital, Cork, Ireland \\ ${ }^{2}$ Department of Otolaryngology — Head and Neck Surgery, South Infirmary Victoria University Hospital, Cork, Ireland \\ ${ }^{3}$ Department of Surgery, Cork University Hospital, Cork, Ireland \\ ${ }^{4}$ Department of Medical Oncology, South Infirmary Victoria University Hospital, Cork, Ireland \\ ${ }^{5}$ Department of Pathology, Cork University Hospital, Cork, Ireland \\ ${ }^{6}$ ENTO Research Institute, College of Medicine and Health, University College Cork, Ireland
}

\begin{abstract}
Backround: The purpose of this study is to assess the impact of trimodal therapy [surgery, chemotherapy and external beam radiotherapy (EBRT)] in patients with anaplastic thyroid cancer (ATC) treated with curative intent.

Materials and methods: Retrospective review of patients with ATC treated at a tertiary referral centre between January 2009 and June 2020. Data were collected regarding demographics, histology, staging, treatment and outcomes.

Results: Seven patients ( 4 female) were identified. Median age was 58 years (range 52-83 years). All patients received EBRT with concurrent doxorubicin. Six patients received surgery followed by chemoradiotherapy (CRT), and one underwent neoadjuvant CRT followed by surgery. Median radiological tumour size was $50 \mathrm{~mm}$ (range $40-90 \mathrm{~mm}$ ). Six patients had gross extrathyroidal extension and three had $\mathrm{N} 1 \mathrm{~b}$ disease. Prescribed radiotherapy schedules were $46.4 \mathrm{~Gy}$ in 29 bidaily fractions $(n=2$, treated 2010), 60 Gy in 30 daily fractions $(n=2), 66$ Gy in 30 fractions $(n=2)$ and 70 Gy in 35 fractions ( $n=1$; patient received neoadjuvant (RT). CRT was discontinued early for two patients due to toxicities. At median follow up of 5.8 months, 42.9\% (3/7) patients were alive and disease-free. Only one patient developed a local failure. Three patients died from distant metastases without locoregional recurrence.

Conclusions: Despite poor prognosis of ATC, selected patients with operable tumours may achieve high locoregional control rates with trimodal therapy, with possibility of long-term survival in select cases.
\end{abstract}

Key words: anaplastic; thyroid; surgery; chemotherapy; radiotherapy

Rep Pract Oncol Radiother 2021;26(3):416-422

\section{Introduction}

Anaplastic thyroid cancer (ATC) is a rare, aggressive malignancy. It accounts for less than $5 \%$ of thyroid cancers, but over half of thyroid cancer-related mortalities [1-3]. Patients usually present with a rapidly enlarging neck mass and symptoms of invasion of nearby structures, including recurrent laryngeal nerve, larynx, trachea and oesophagus. Symptoms include dysphagia, hoarseness, stridor and dyspnoea [4]. More than $70 \%$ of patients have tumour infiltration of surrounding tissues, more than $75 \%$ have cervical nodal metastases and $50 \%$ have distant metastatic disease at presentation [1, 4]. Most cases are inoperable at presentation due to invasion of carotid arteries, prevertebral fascia,

Address for correspondence: Dr Orla A. Houlihan, Department of Radiation Oncology, Glandore Radiotherapy Centre, Cork University Hospital, Wilton, Cork; tel: +353 (0)1 852 8416; e-mail: orla.houlihan@slh.ie

This article is available in open access under Creative Common Attribution-Non-Commercial-No Derivatives 4.0 International (CC BY-NC-ND 4.0) license, allowing to download articles and share them with others as long as they credit the authors and the publisher, but without permission to change them in any way or use them commercially 
and superior mediastinum [5]. Prognosis is grave, with studies reporting one year survival of less than $20 \%$ and a median survival of less than six months $[6,7]$. Most deaths occur due to uncontrolled local disease [1].

Some studies have found aggressive treatment with trimodal therapy [surgery, chemotherapy and external beam radiotherapy (EBRT)] can improve outcomes, specifically locoregional recurrence free survival, which can improve patients' quality of life given the local aggressiveness of ATC $[6,7]$.

Doxorubicin is the systemic agent most reported in the literature and is given concurrently with EBRT [6-10]. This is the regimen used in our cancer centre.

The purpose of our study was to examine the outcomes for patients with a diagnosis of ATC who received trimodal therapy in our cancer centre and to compare these outcomes with the published literature.

\section{Materials and methods}

The present study comprised a retrospective review of patients undergoing trimodal therapy for ATC at our institution between January 2009 and June 2020. Ethical approval was granted by the institution's clinical research ethics committee. All patients presenting to our institution with ATC are discussed at the multidisciplinary Head and Neck Cancer meeting. Patients are considered for primary surgical treatment in cases which are considered operable, usually based on no gross radiological encasement of carotid arteries, invasion of prevertebral muscle, direct invasion of superior mediastinum, or extensive aerodigestive tract invasion; and with no evidence of distant metastases.

Adjuvant chemoradiotherapy (CRT) (with doxorubicin $10-20 \mathrm{mg} / \mathrm{m}^{2} \mathrm{IV}$ ) was offered to patients with a good performance status and either stage IVA or IVB disease. Pre-operative imaging, operative notes and pathological reports helped to define the treatment volumes. For adjuvant EBRT using three dimensional conformal radiation therapy (3DCRT) and volumetric modulated radiation therapy (VMAT), the high dose volume included the surgical thyroid bed and involved nodal levels with an elective volume to cervical levels II-VI and superior mediastinum if not already included in the high dose region.
Radiotherapy, histopathological, pharmacy and surgical databases of the treating institutions were searched for patients diagnosed with ATC during the study period. Data were collected regarding demographics, histology, staging, treatment and outcomes. Study endpoints were local recurrence, the development of metastatic disease and death from any cause. Median follow up was from the date of primary surgery to the last known clinical or radiological review. Tumours were staged according to the TNM Classification of Malignant Tumours $8^{\text {th }}$ edition [11]. Clinical notes, histopathology reports and clinical imaging were reviewed for each patient. Toxicity data was recorded according to the National Cancer Institute Common Terminology Criteria for Adverse Events (CTCAE) grading system [12].

\section{Results}

\section{Patients and tumour characteristics}

25 patients with a diagnosis of ATC between January 2009 and June 2020 were identified. Of these, seven patients received trimodal therapy and formed our study population. The remaining patients were considered to have tumours which were inoperable or to be unfit for surgery.

The tumour characteristics for included patients are summarised in Table 1 . Median age at commencement of treatment was 58 years (range 52-83 years). Four patients were female, and three were male. Six patients had gross extrathyroidal extension and three had lateral neck metastases (N1b disease) at diagnosis. Local structures invaded at diagnosis included the infrahyoid muscles $(n=5)$, internal jugular vein $(\mathrm{n}=4)$, constrictor muscles $(\mathrm{n}=2)$, thyroid cartilage $(\mathrm{n}=2)$, sternocleidomastoid muscle $(n=2)$, oesophagus $(n=1)$, prevertebral muscle $(\mathrm{n}=1)$ and common carotid artery $(\mathrm{n}=1)$.

No patient had distant metastases at diagnosis. The median radiological tumour size was $50 \mathrm{~mm}$ (range 40-90 $\mathrm{mm}$ ) and pathological tumour size was $66 \mathrm{~mm}$ (range $43-110 \mathrm{~mm}$ ). Two patients had coexistent differentiated thyroid carcinoma (papillary-follicular variant and follicular). In both of these cases ATC was present as a major component. BRAF mutation testing was implemented in the treating institution in 2018 and the three patients who were diagnosed following this were BRAF mutation negative. 
Table 1. Tumour characteristics

\begin{tabular}{|l|c|c|c|c|c|}
\hline $\begin{array}{l}\text { Patient } \\
\text { number }\end{array}$ & $\begin{array}{c}\text { Stage } \\
\text { (TNM 8) }\end{array}$ & $\begin{array}{c}\text { Radiological } \\
\text { tumour size [mm] }\end{array}$ & $\begin{array}{c}\text { Pathological tumour } \\
\text { size [mm] }\end{array}$ & $\begin{array}{c}\text { Coexistent differentiated thyroid } \\
\text { carcinoma }\end{array}$ & $\begin{array}{c}\text { Gross extrathyroidal } \\
\text { extension }\end{array}$ \\
\hline 1 & T3aN0 & 40 & 43 & Yes (papillary - follicular variant) & No \\
\hline 2 & T4bN1b & 50 & N/A & No & Yes \\
\hline 3 & T4aN1b & 50 & 72 & No & Yes \\
\hline 4 & T4bN0 & 67 & 110 & Yes (follicular) & Yes \\
\hline 5 & T4bN0 & 90 & 100 & No & Yes \\
\hline 6 & T4aN0 & 45 & 55 & No & Yes \\
\hline 7 & T4aN1b & 49 & 60 & & \\
\hline
\end{tabular}

\section{Treatment characteristics}

Treatment characteristics are summarised in Table 2 . Six patients were treated with surgery followed by adjuvant CRT. One patient received neoadjuvant CRT followed by surgery. This patient had tumour which was considered inoperable at initial presentation due to invasion of the right common carotid artery, but was rendered operable by CRT. All patients underwent total thyroidectomy, with five patients also undergoing lateral neck dissection. In all cases, complete macroscopic clearance of all tumour, thyroid tissue, and nodal disease was achieved. One patient's recurrent laryngeal nerve was sacrificed during surgery in order to achieve gross total resection. No patient underwent tracheostomy.
Once daily radiotherapy doses ranged from 60 Gy to 70 Gy. The higher dose of 70 Gy was prescribed given the neo-adjuvant timing of radiotherapy. The decision of whether to treat with $60 \mathrm{~Gy}$ or $66 \mathrm{~Gy}$ for the remaining cases was made by the treating radiation oncologist. Doxorubicin doses were prescribed by the treating medical oncologist and ranged from 10 to $20 \mathrm{mg} / \mathrm{m}^{2}$. CRT was discontinued early for two patients due to toxicities including dysphagia, fatigue and radiation dermatitis. Both patients required admission during their radiotherapy for management of the toxicities. Patient 1 received 52 Gy out of planned 60 Gy. Patient 3 received 60 Gy out of planned $66 \mathrm{~Gy}$.

Table 2. Treatment characteristics

\begin{tabular}{|c|c|c|c|c|c|c|c|}
\hline $\begin{array}{l}\text { Patient } \\
\text { number }\end{array}$ & $\begin{array}{c}\text { Neoadjuvant } \\
\text { or adjuvant } \\
\text { CRT }\end{array}$ & $\begin{array}{l}\text { Extent of } \\
\text { surgical } \\
\text { resection }\end{array}$ & $\begin{array}{l}\text { Doxorubicin dose } \\
{\left[\mathrm{mg} / \mathrm{m}^{2}\right]} \\
\text { (Number of cycles; } \\
\text { frequency) }\end{array}$ & $\begin{array}{l}\text { Delivered } \\
\text { radiotherapy } \\
\text { dose/ } \\
\text { /fractionation } \\
\text { schedule } \\
\text { [Gy/fraction] }\end{array}$ & $\begin{array}{l}\text { Prescribed } \\
\text { radiotherapy } \\
\text { dose/ } \\
\text { /fractionation } \\
\text { schedule } \\
\text { [Gy/fraction] }\end{array}$ & $\begin{array}{l}\text { Radiotherapy } \\
\text { technique }\end{array}$ & $\begin{array}{l}\text { Reason for early } \\
\text { discontinuation } \\
\text { of CRT }\end{array}$ \\
\hline 1 & Adjuvant & Ro & 20 (5; once weekly) & $52 / 26$ & $60 / 30$ & VMAT & $\begin{array}{l}\text { Dysphagia, } \\
\text { radiation } \\
\text { dermatitis }\end{array}$ \\
\hline 2 & Neoadjuvant & Ro & 10 (7; once weekly) & $70 / 35$ & $70 / 35$ & 3DCRT & $\mathrm{N} / \mathrm{A}$ \\
\hline 3 & Adjuvant & Ro & 10 (4; once weekly) & $60 / 30$ & $66 / 33$ & 3DCRT & $\begin{array}{l}\text { Dysphagia, } \\
\text { fatigue }\end{array}$ \\
\hline 4 & Adjuvant & Ro & 10 (7; once weekly & $66 / 33$ & $66 / 33$ & 3DCRT & $\mathrm{N} / \mathrm{A}$ \\
\hline 5 & Adjuvant & $\mathrm{R} 1$ & $\begin{array}{c}15(14 ; \text { once weekly } \\
\times 2 \text { weeks for initial } \\
2 \text { cycles, then once weekly } \\
\times 3 \text { weeks followed by } \\
1 \text { week gap for remaining } \\
12 \text { cycles) }\end{array}$ & $60 / 30$ & $60 / 30$ & 3DCRT & $\mathrm{N} / \mathrm{A}$ \\
\hline 6 & Adjuvant & Ro & 20 (13; once weekly) & $46.4 / 29$ bidaily & 46/29 bidaily & 2DRT & N/A \\
\hline 7 & Adjuvant & Ro & 10 (17; once weekly) & $46.4 / 29$ bidaily & 46/29 bidaily & 2DRT & $\mathrm{N} / \mathrm{A}$ \\
\hline
\end{tabular}

CRT - chemoradiotherapy; R0 - microscopically margin-negative resection; R1 - microscopic margins positive for tumour; VMAT — volumetric modulated arc therapy; 3DCRT - 3D-conformal radiation therapy; 2DRT - conventional (2D) radiation therapy 
Table 3. Patient outcomes

\begin{tabular}{|l|c|c|c|}
$\begin{array}{l}\text { Patient } \\
\text { Number }\end{array}$ & Local/distant recurrence & $\begin{array}{c}\text { Time from surgery to most recent review/ } \\
\text { /progression of disease (months) }\end{array}$ & Time from surgery to death (months) \\
\hline 1 & N/A & 3.8 & N/A \\
\hline 2 & N/A & 9.8 & 9.3 \\
\hline 3 & Local recurrence & 5.3 & 4.6 \\
\hline 4 & Pulmonary metastases & 4.2 & N/A \\
\hline 5 & N/A & 42.9 & 9.1 \\
\hline 6 & Pulmonary metastases & 6.6 & 7.4 \\
\hline 7 & Pulmonary metastases & 5.8 & \\
\hline
\end{tabular}

Table 4. Toxicities

\begin{tabular}{|l|c|c|c|c|c|c|}
\hline $\begin{array}{l}\text { Patient } \\
\text { number }\end{array}$ & $\begin{array}{c}\text { Dermatitis } \\
\text { (CTCAE grade) }\end{array}$ & $\begin{array}{c}\text { Dysphagia } \\
\text { (CTCAE grade) }\end{array}$ & $\begin{array}{c}\text { Fatigue } \\
\text { (CTCAE grade) }\end{array}$ & $\begin{array}{c}\text { Anaemia } \\
\text { (CTCAE grade) }\end{array}$ & $\begin{array}{c}\text { PEG/RIG feeding } \\
\text { required }\end{array}$ & $\begin{array}{c}\text { Admission } \\
\text { during treatment }\end{array}$ \\
\hline 1 & 3 & 3 & 2 & 2 & Yes & Yes \\
\hline 2 & 2 & 2 & 2 & 0 & No & No \\
\hline 3 & 3 & 3 & 3 & 2 & Yes & Yes \\
\hline 4 & 2 & 2 & 2 & 3 & No & No \\
\hline 5 & 3 & 4 & 2 & 2 & Yes & No \\
\hline 6 & 1 & 1 & 1 & 1 & No & No \\
\hline 7 & 0 & 0 & 0 & 1 & No & No \\
\hline
\end{tabular}

CTCAE - National Cancer Institute Common Terminology Criteria for Adverse Events

\section{Outcomes}

The outcomes for each patient following trimodal therapy are summarised in Table 3. Median follow up was 5.8 months (range 3.8-42.9 months) for all patients and 9.8 months (range 3.8-42.9 months) for surviving patients. At the time of writing, $42.9 \%$ (3/7) patients are alive and disease-free. One patient developed local recurrence and three developed distant metastases following treatment. These patients received palliative care input for management of symptoms including pain and dyspnoea, and nutritional support. All four patients who developed disease recurrence died. The patient who received neoadjuvant CRT had a complete pathological response at the time of surgery. This patient remains alive and disease-free at 9.8 months following surgical resection.

\section{Toxicities}

Acute CRT toxicities are shown in Table 4. Due to a short follow-up, late side effects were not recorded.

\section{Discussion}

In this study, we found the combination of surgery and concurrent doxorubicin-based CRT to be highly effective in controlling local disease, with 6/7 patients achieving local control. Given that most patients die from uncontrolled local disease with high rates of local recurrence, local control is paramount in maintaining quality of life. Moreover, 3/7 patients had no recurrence of anaplastic carcinoma at the time of writing; however, the length of follow-up for two of these is less than one year. These findings would support trimodal treatment for patients with ATC who are considered operable at presentation, or who are rendered operable by CRT.

The two patients who received $46 \mathrm{~Gy}$ in 29 bidaily fractions were treated in 2010. This fractionation schedule is described in a paper by Tennvall et al. [8] which reports on three protocols combining doxorubicin, hyperfractionated radiotherapy and surgery. Bidaily fractionation regimens for ATC were reported on in several studies from 2002 to 2009 as being well tolerated and associated with improved local control and median survival when given as part of multimodal treatment $[6,8,10$, 13]. There was an institutional transition following this to daily fractionation schedules, as has been the case in more recently published studies, which have found a dose-response relationship 
with EBRT and improved outcomes with doses of $\geq 50-60$ Gy. Radiotherapy doses vary in the literature, as in our study and range from $<50$ to 70 Gy $[7,9]$.

In our study, the treatment technique evolved over time from a two dimensional planning technique (2DRT) in which an anterior and posterior beam arrangement was employed from orthogonal imaging with a posterior spinal cord block, through 3DCRT with the Eclipse treatment planning system (TPS) (Varian Medical Systems, Palo Alto, CA), to intensity modulated radiation therapy (IMRT) with VMAT in 2020 Monaco TPS (Elekta CMS, Maryland Heights, MO, USA).

While Table 4 appears to reflect reduced toxicity for patients treated with 2DRT compared with 3DCRT and reduced toxicity with 3DCRT compared with VMAT, we noted documentation of toxicities improved with time and we believe that this, along with the lower total dose of 46 Gy in 29 bidaily fractions delivered with 2DRT, is the reason for these discrepancies. We provide table 4 to highlight the most common toxicities experienced during trimodal therapy for anaplastic thyroid carcinoma rather than for a comparison between techniques.

This study demonstrates that the potential exists for survival of at least years following treatment for ATC in select patients. One patient remains disease-free 42.9 months and another 9.8 months following surgical resection. The third patient who remains alive recently completed treatment and has been well to date. This trend has also been reported in several studies, with a minority of patients surviving for several years following the trimodal treatment $[6,8]$. The patient who is disease-free at 42.9 months post-surgery had co-existent differentiated thyroid carcinoma which has been reported to be associated with improved outcomes [7]. While it is interesting to note that survival following diagnosis of distant metastases (0.2, 1.4 and 2.5 months) was shorter than survival following local recurrence (4 months), further interpretation is precluded due to the small size of the study.

Only one of the seven patients (14.2\%) developed locoregional recurrence. Given the potential morbidity associated with local invasion and mechanical compression of nearby structures by the primary tumour, trimodal therapy may have a role in symptom prevention and reduced morbidity even for those patients who subsequently develop distant metastases [14]. It is essential, therefore, that all patients with a diagnosis of ATC are referred to specialist centres and are discussed in a multidisciplinary team setting.

Despite aggressive multimodal treatment, the prognosis of ATC remains grave. The study and development of alternative therapeutic strategies is essential in order to improve the quality of life and prognosis of affected patients. Immunotherapeutic agents, including pembrolizumab [15], atezolizumab [16], tyrosine kinase inhibitors such as levatinib $[17,18]$ and oncolytic virus therapy $[19,20]$ are currently under investigation and have demonstrated promising results in preliminary trials.

The complete pathological response in the patient who completed neoadjuvant CRT demonstrates the potential responsiveness of ATC to CRT. In the future, molecular diagnosis and targeted treatment may replace doxorubicin-based neoadjuvant CRT in inoperable cases. Several studies have investigated the impact of genetic activations, such as the mutational activation of BRAF on potential treatment options. Targeted therapy with dabrafenib, a BRAF inhibitor, and trametinib, a MEK inhibitor, has been shown to be an effective treatment approach in BRAF mutated ATC $[21,22]$. When used in the neoadjuvant setting, this regimen has demonstrated a high pathological response rate with one case series reporting 100\% locoregional control rates and overall survival of $100 \%$ and $83 \%$ at six months and one year, respectively [23]. Next generation sequencing analysis, where available, can characterise the cancer genome, identify targetable mutations, and guide systemic treatment decisions [24]. The continuous evolution of targeted therapy tailored to molecular mutations may significantly change our treatment of ATC in the future.

However, at present, we would recommend surgery as a first line approach in all cases of ATC that are considered operable at presentation, with neoadjuvant treatment reserved only for cases considered inoperable. Limitations of the study include the retrospective nature, small cohort, and the short follow-up for surviving patients. Radiotherapy and doxorubicin doses varied between patients. Decisions regarding doses, however, were made individually for each patient taking the extent of dis- 
ease, comorbidities and performance status into consideration. While inhomogeneities exist in the treatment group, this paper reflects outcomes for patients treated in clinical practice._Given that most recurrences of ATC occur very soon after treatment [5], we believe that our findings regarding local control are meaningful.

\section{Conclusions}

ATC has a poor prognosis with high rates of recurrence and mortality. In some patients, trimodal therapy can be associated with a good outcome, with one of our patients remaining disease-free more than three years following treatment.

\section{Conflict of interest}

The authors declare that they have no conflicts of interest.

\section{Funding}

None declared.

\section{References}

1. Chiacchio S, Lorenzoni A, Boni G, et al. Anaplastic thyroid cancer: prevalence, diagnosis and treatment. Minerva Endocrinol. 2008; 33(4): 341-357, indexed in Pubmed: 18923370.

2. Gilliland FD, Hunt WC, Morris DM, et al. Prognostic factors for thyroid carcinoma. A population-based study of 15,698 cases from the Surveillance, Epidemiology and End Results (SEER) program 1973-1991. Cancer. 1997; 79(3): 564-573, doi: 10.1002/(sici)10970142(19970201)79:3<564::aid-cncr20>3.0.co;2-0, indexed in Pubmed: 9028369.

3. Landis SH, Murray T, Bolden S, et al. Cancer statistics, 1998. CA Cancer J Clin. 1998; 48(1): 6-29, doi: 10.3322/ canjclin.48.1.6, indexed in Pubmed: 9449931.

4. Are C, Shaha AR. Anaplastic thyroid carcinoma: biology, pathogenesis, prognostic factors, and treatment approaches. Ann Surg Oncol. 2006; 13(4): 453-464, doi: 10.1245/ASO.2006.05.042, indexed in Pubmed: 16474910.

5. Rao SN, Zafereo M, Dadu R, et al. Patterns of Treatment Failure in Anaplastic Thyroid Carcinoma. Thyroid. 2017; 27(5): 672-681, doi: 10.1089/thy.2016.0395, indexed in Pubmed: 28068873.

6. Swaak-Kragten AT, de Wilt JHW, Schmitz PIM, et al. Multimodality treatment for anaplastic thyroid carcinoma-treatment outcome in 75 patients. Radiother Oncol. 2009; 92(1): 100-104, doi: 10.1016/j.radonc.2009.02.016, indexed in Pubmed: 19328572.

7. Fan D, Ma J, Bell AC, et al. Outcomes of multimodal therapy in a large series of patients with anaplastic thyroid cancer. Cancer. 2020; 126(2): 444-452, doi: 10.1002/cncr.32548, indexed in Pubmed: 31593317.
8. Tennvall J, Lundell G, Wahlberg P, et al. Anaplastic thyroid carcinoma: three protocols combining doxorubicin, hyperfractionated radiotherapy and surgery. $\mathrm{Br} J$ Cancer. 2002; 86(12): 1848-1853, doi: 10.1038/sj.bjc.6600361, indexed in Pubmed: 12085174.

9. Sherman EJ, Lim SuH, Ho AL, et al. Concurrent doxorubicin and radiotherapy for anaplastic thyroid cancer: a critical re-evaluation including uniform pathologic review. Radiother Oncol. 2011; 101(3): 425-430, doi: 10.1016/j.radonc.2011.09.004, indexed in Pubmed: 21981877.

10. Kim JH, Leeper RD, Kim JH, et al. Combination adriamycin and radiation therapy for locally advanced carcinoma of the thyroid gland. Int J Radiat Oncol Biol Phys. 1983; 9(4): 565-567, doi: 10.1016/0360-3016(83)90076-7, indexed in Pubmed: 6406402.

11. Brierley JD, Gospodarowicz MK, Wittekind CT. Classification of Malignant Tumours. 8th ed. John Wiley \& Sons, Hoboken 2017.

12. National Cancer Institute. Common Terminology Criteria for Adverse Events (CTCAE) v5.0. 2017. https://ctep.cancer. gov/protocoldevelopment/electronic_applications/ctc. htm\#ctc_50 (2020 Nov 26).

13. Wang Y, Tsang R, Asa S, et al. Clinical outcome of anaplastic thyroid carcinoma treated with radiotherapy of onceand twice-daily fractionation regimens. Cancer. 2006; 107(8): 1786-1792, doi: 10.1002/cncr.22203, indexed in Pubmed: 16967442.

14. Nilsson O, Lindeberg J, Zedenius J, et al. Anaplastic giant cell carcinoma of the thyroid gland: treatment and survival over a 25-year period. World J Surg. 1998; 22(7): $725-730$, doi: 10.1007/s002689900460, indexed in Pubmed: 9606289.

15. Aghajani MJ, Cooper A, McGuire H, et al. Pembrolizumab for anaplastic thyroid cancer: a case study. Cancer Immunol Immunother. 2019; 68(12): 1921-1934, doi: 10.1007/s00262-019-02416-7, indexed in Pubmed: 31637475.

16. Naoum GE, Morkos M, Kim B, et al. Novel targeted therapies and immunotherapy for advanced thyroid cancers. Mol Cancer. 2018; 17(1): 51, doi: 10.1186/s12943-0180786-0, indexed in Pubmed: 29455653.

17. Iwasaki H, Yamazaki H, Takasaki $H$, et al. Lenvatinib as a novel treatment for anaplastic thyroid cancer: A retrospective study. Oncol Lett. 2018; 16(6): 72717277, doi: 10.3892/ol.2018.9553, indexed in Pubmed: 30546466.

18. Tahara M, Kiyota N, Yamazaki T, et al. Lenvatinib for Anaplastic Thyroid Cancer. Front Oncol. 2017; 7: 25, doi: 10.3389/ fonc.2017.00025, indexed in Pubmed: 28299283.

19. Malfitano AM, Somma SDi, Prevete $N$, et al. Virotherapy as a Potential Therapeutic Approach for the Treatment of Aggressive Thyroid Cancer. Cancers (Basel). 2019; 11(10), doi: 10.3390/cancers11101532, indexed in Pubmed: 31636245.

20. Guan M, Romano G, Coroniti R, et al. Progress in oncolytic virotherapy for the treatment of thyroid malignant neoplasm. J Exp Clin Cancer Res. 2014; 33: 91, doi: 10.1186/ s13046-014-0091-8, indexed in Pubmed: 25366264.

21. Iyer PC, Dadu R, Ferrarotto R, et al. Real-World Experience with Targeted Therapy for the Treatment of Anaplastic Thyroid Carcinoma. Thyroid. 2018; 28(1): 79-87, doi: 10.1089/ thy.2017.0285, indexed in Pubmed: 29161986. 
22. Subbiah V, Kreitman RJ, Wainberg ZA, et al. Dabrafenib and Trametinib Treatment in Patients With Locally Advanced or Metastatic BRAF V600-Mutant Anaplastic Thyroid Cancer. J Clin Oncol. 2018; 36(1): 7-13, doi: 10.1200/ JCO.2017.73.6785, indexed in Pubmed: 29072975.

23. Wang J, Zafereo M, Dadu R, et al. Complete Surgical Resection Following Neoadjuvant Dabrafenib Plus
Trametinib inBRAFV600E-Mutated Anaplastic Thyroid Carcinoma. Thyroid. 2019; 29(8): 1036-1043, doi: 10.1089/ thy.2019.0133, indexed in Pubmed: 31319771.

24. De Leo S, Trevisan M, Fugazzola L. Recent advances in the management of anaplastic thyroid cancer. Thyroid Res. 2020; 13(1): 17, doi: 10.1186/s13044-020-00091-w, indexed in Pubmed: 33292371. 